\title{
FAMÍLIA, SOCIEDADE E EDUCAÇÃO: um ensaio sobre individualismo, amor líquido e cultura pós-moderna
}

FAMILY, SOCIETY AND EDUCATION: an essay about individualism, liquid love and post-modern culture

\author{
Eduardo Carlos Bianca Bittar ${ }^{1}$
}

\begin{abstract}
Resumo:
A presente investigação retira força do interior da reflexão frankfurtiana, especialmente com Horkheimer, Habermas e Fromm, e se propõe a pensar criticamente os desafios, trazidos pela sociedade capitalista, à idéia de família, na medida em que se constatam alterações profundas na estrutura de produção e na estruturação da formação do indivíduo no seio da família, chegando-se à constatação de que a perda da autonomia é o maior risco para o indivíduo.

Palavras-Chave: Individualismo. Família. Pós-modernidade.

Abstract:

The present investigation grows from the Frankfurt refletions, specially Horkheimer, Habermas and Fromm, and proposes to think critically about the challanges, brought by the capitalist society, to the idea of family, as we see deep changes in the production structures and in the strutucturing of the individual within the family, finally getting the finding that the loss of autonomy is the biggest danger to the individual.
\end{abstract}

Keywords: Individualism. Family. Post-modernity.

\section{Problematização}

A idéia de família sofre reajustes históricos. Na medida em que isto cria constrangimentos práticos, cujas alterações estruturais trazem conseqüências sociais quantificáveis, o próprio direito de família se vê constrangido a pensar e a entender a origem destas alterações, até mesmo com vistas à produção de algum tipo de diagnóstico na temática.

Estas conseqüências se sentem e se metrificam por uma série de investigações empíricas contemporâneas, e o estudo da sintomatologia social parece ser suficientemente

\footnotetext{
Livre-Docente e Doutor. Professor Associado do Departamento de Filosofia e Teoria Geral do Direito da Faculdade de Direito da Universidade de São Paulo (USP). Professor e Pesquisador do Programa de Mestrado em Direitos Humanos do UnifIEO. Presidente da Associação Nacional de Direitos Humanos (ANDHEP). Pesquisador-Sênior do Núcleo de Estudos da Violência (NEV-USP). Membro do Grupo de Conjuntura Internacional da USP (GACINT). Membro Titular da Cátedra UNESCO para a Paz, Democracia, Direitos Humanos e Tolerância (IEA-USP). Membro do Conselho Editorial da Revista da Faculdade de Direito da Universidade de São Paulo.
} 
retórico para apontar no sentido da necessidade do aprofundamento das investigações e pesquisas em torno do problema da família contemporânea e seu sentido.

E, nesse sentido, as perguntas seguintes colaboram para o processo de ajustamento da reflexão a seus pontos problemáticos: como unidade de definição da interelação entre sociedade, cultura e personalidade, lugar de revezamento entre ócio e trabalho, prazer e dor, conservação da intimidade erótica e de exposição pública, não estaria a família sendo afetada pela mudança do modo de produção?; as alterações do modo de produção estão afetando a estrutura da família e lhe causando que tipo de desgastes?; como unidade protoformadora da personalidade e da sociedade, nestas condições, não estaria a família ameaçada?; sua ameaça não representa também uma ameaça para o indivíduo, tanto do ponto de vista psíquico, quanto do ponto de vista social?

A enquête contida nesta investigação procura investigar e trazer algumas luzes para o enfrentamento destas questões.

2. Individualismo, consumismo e estetismo: a sociedade da sensação

A sociedade contemporânea vivencia uma experiência de sobressalente ênfase cultural no indivíduo. Na emergência do indivíduo, a propaganda e o consumismo são duas determinantes fundamentais a delimitar a profunda estetização da experiência. ${ }^{2}$ Se há múltiplas opções de vida, e as regras tradicionais de controle social e moral do comportamento já não servem mais, somente sobra um leque diversificado de alternativas de auto-afirmação, o que permite aos indivíduos serem aquilo que vestem ou aquilo que os lugares que freqüentam significam.

A criação de diversos modos de entrada no mercado é mais do que a revelação da benesse do mercado para com a diversidade, e mais um modo de multiplicação das práticas do próprio mercado no sentido de sua re-invenção permanente. A reificação alcança nuances muito específicas, a ponto de condicionar a identidade de indivíduos, grupos e comunidades. O autoreconhecimento do indivíduo por ele mesmo parte de sua disposição para consumir este ou aquele insumo da indústria cultural. A seleção de fatias de mercado, seja emo, seja cult, seja descolado, seja neohippie, não importa a escolha, trata-se sempre de uma escolha no mercado, ao que foi reduzido o exercício da liberdade.

\footnotetext{
2 O registro da identidade desta época é: "Le moment post-moderne est bien davantage qu'une mode, il révèle le procès de l'indifférence pure en ce que tous les goûts, tous les comportements peuvent cohabiter sans s'exclure, tout peut être choisi à loisir, le plus opérationnel comme le plus ésotérique, le nouveau comme l'ancien, la vie simple-écologiste comme la vie hypersophistiquée, dans um temps dévitalisé sans repère stable, sans coordonnée majeure" (LIPOVETSKY, Gilles. L'Ere du Vide: essais sur l'individualisme contemporain. Paris: Gallimard, 1983. p. 58).
} 
A liberdade é a liberdade de escolhas no interior da lógica do mercado. A sociedade pós-moderna é a sociedade da sensação, ou seja, a sociedade em que o estético se torna ontológico, na versão de Türke. ${ }^{3}$

Nesse momento, se existem dois modos de vida, o modo ser e o modo ter, o nosso momento é de prevalência do modo ter, para seguir as lições de Erich Fromm a respeito do tema. Assim, até mesmo ser e ter se confundem. Isto porque a reificação dos valores torna possível que o ser de nosso tempo se esgote no modo ter, e considerar que se pode ter o ser. Nossa época, dessa forma paradoxal, é a do ser o ter, e ter o ser. Dupla possessividade produz um louvor a um duplo materialismo, o que subverte os valores para antepor a eles as coisas, e o que faz com que os valores se alojem, no interior das coisas mesmas. O indivíduo se coisifica no que tem, e espiritualiza as coisas que possui. Isso significa a objetificação da vida. ${ }^{4}$ Estamos numa sociedade focada nas coisas e não nas pessoas, de modo que o que se tem é um modelo prevalecente responsável por produzir uma sociedade doente. ${ }^{5}$ A sociedade assim fundada é aquela que foi assenhoreada pela dinâmica do capital. ${ }^{6}$ A sociedade assim definida nada mais é do que uma sociedade que exibe o seu caráter anal de forma sistêmica e neurótica. ${ }^{7}$

Alter e ego, inflados de si mesmos, não constróem pontes de equivalência relacional, determinando condições pelas quais o que vige é uma idéia de liberdade em que "cada um é cada um, e ponto". A solidão do indivíduo na condição deste "cada um" de ambos os pólos se torna uma conseqüência óbvia da inviabilidade do entendimento. Os esforços de tolerância são somente os substitutivos para a decrepitude dos esforços por entendimento.

Há a imagem ideológica de que a liberdade aumentou e que o indivíduo é de fato mais livre do que ontem; no entanto, esta idéia de liberdade é a de uma liberdade de

\footnotetext{
3 "Dessa forma, o bem e o mal se transformam em categorias estéticas; e o estético se transforma no ontológico, ou seja, na possibilidade ser ou não ser" (TÜRKE, Christoph. Sociedade da sensação: a estetização da luta pela existência. In: ZUIN, Antonio A. S.; PUCCI, Bruno; RAMOS DE OLIVEIRA, Newton. Ensaios frankfurtianos. São Paulo: Cortez, 2004. p. 64).

4 "O modo ter de existência não se estabelece por um processo vivo e criativo entre o sujeito e o objeto; ele transforma em coisas tanto o sujeito como o objeto. A relação é de inércia, e não de vida" (FROMM, Erich. Ter ou Ser? Tradução de Nathanael C. Caixeiro. 4. ed. São Paulo: LTC, 1987. p. 88).

5 “Até este ponto, o argumento em questão tem sido de que os traços de caráter engendrados por nosso sistema socioeconômico, isto é, por nosso modo de vida, são patogênicos e de fato produzem uma pessoa doente, e, por conseguinte, uma sociedade doente" (Id. Ibid., p. 29).

6 "A natureza do modo ter de existência decorre da natureza da propriedade privada" (Id. Ibid., p. 87).

7 "O que importa é o parecer de Freud segundo o qual a tendência predominante à posse ocorre no período anterior à obtenção de plena maturidade e é patológica se se tornar permanente. Em outras palavras, para Freud, uma pessoa que se ocupe exclusivamente em adquirir e possuir é uma pessoa neurótica, mentalmente doente; segue-se disto que uma sociedade em que a maioria de seus membros exibe o caráter anal é uma sociedade doente" (Id. Ibid., p. 93).
} 
consumo, da auto-afirmação da identidade pelo consumo. Apesar da impressão de aumento de liberdade, o homem pós-moderno vive o paradoxo do aumento da dependência do mercado e da fragilidade pessoal. O que se tem aqui é uma subjetividade ameaçada de sossobrar sob as forças do mercado, distante, portanto, da capacidade de emancipação.

O indivíduo pós-moderno não é livre, senão em imagens evocadas por outdoors e propagandas televisivas; ele é controlado, monitorado, determinado e insculpido pelos fluxos e refluxos do mercado. Sua essência está fora de si; sua essência não é autoconsciência, mas heteroconsciência. ${ }^{8}$ Se o mercado se incrementa a todo tempo, se estar no mercado significa enfrentar a concorrência infinitamente crescente dos competidores, o mercado só pode ser visto como o lugar de permanente projeção do novo. Não importa o que seja e do que se trate, o sucesso do novo está em sua aprovação e consolidação como um novo aceito, ou seja, o próprio ato de consumo se torna uma forma de mensuração da plausibilidade da novidade.

Onde tudo é sempre novo e as pressões estão no sentido de forçar o novo, o indivíduo que está sempre "antenado" no novo, se torna ele-mesmo uma novidade permanente, que exige do sujeito mais do que a capacidade de comprar, a flexibilidade de adaptar-se à dinâmica dos tempos (leia-se do timing do mercado). Diante de uma oferta sempre gigantesca e inventiva, a multiplicidade de escolhas é uma conseqüência óbvia. Em verdade, a questão das comunidades parece ser a resposta social à geração sempre inquietante das insuficiências do antigo geradas pelo mercado. O motor que acelera o mercado, também acelera as formas de desarranjo dos laços sociais, gera o envelhecimento do que fica, aumentando a sensação de perda de referenciais para a ação dos indivíduos. A ansiedade pelo que se terá já está disseminada no imaginário coletivo, antes mesmo da coleção de inverno chegar! ${ }^{9}$

Ademais, quanto maior a sensação de liberdade e de afrouxamento dos laços sociais, maior a sensação de mal-estar na pós-modernidade, ou seja, de insegurança, de indeterminação, especialmente considerada a fragilidade na qual está posta a condição de exercício da liberdade. No entanto, num determinado momento, torna-se insuportável

\footnotetext{
8 "Consumir apresenta qualidades ambíguas: alivia a ansiedade, porque o que se tem não pode se tirado; mas exige que se consuma cada vez mais, porque o consumo anterior logo perde a sua característica de satisfazer. Os consumidores modernos podem identificar-se pela fórmula: eu sou = o que tenho e o que consumo" (FROMM, Erich. Ter ou Ser? Tradução de Nathanael C. Caixeiro. 4. ed. São Paulo: LTC, 1987. p. 42).

9 "A necessidade da comunidade estética gerada pela ocupação com a identidade é o campo preferencial que alimenta a indústria do entretenimento: a amplitude da necessidade explica em boa medida o sucesso impressionante e contínuo dessa indústria" (BAUMAN, Zygmunt. Comunidade: a busca por segurança no mundo atual. Tradução de Plínio Dentzien. Rio de Janeiro: Jorge Zahar, 2003. p. 63).
} 
que nada fique e que tudo passe. O indivíduo entra em crise, pois não se vê. A pergunta que acaba sendo feita, geralmente no divã, é onde é que eu fui parar?

O mundo da aparência, da moda, das tendências, do imediatismo, do progresso material, da superafetação das coisas é o mundo do eterno ciclo do consumismo, da redundância que se repete ad perpetuum. É o mundo da infantilização, do quer e do gostar, do não-querer e do não-gostar. Erich Fromm vai mais adiante e afirma: " $A$ atitude inerente no consumismo é a de engolir o mundo todo. O consumidor é a eterna criança de peito berrando pela mamadeira" ${ }^{10} \mathrm{O}$ mundo da aparência é este que conduz massas inteiras a um processo de idiotização - utiliza-se do termo para designar este ato de autocentramento egóico, no sentido grego, sem deixar de carregar consigo o peso retórico que equivale a um xingamento.

\section{Família, economia e sociedade: o peso do social sobre o afetivo}

Afinal, o que se tem acima serve como um retrato, que se constrói no sentido da formação de uma consciência histórica de nosso tempo. No entanto, a investigação sobre as origens desse fenômeno é um outro passo além da preliminar, e necessária, e nem sempre visível, constatação sobre o tempo presente. Cabe, portanto, agora, perguntar como se processa no fluxo dos acontecimentos essa mudança em direção a este estado-de-coisas, especialmente no que tange à questão da família. Essa investigação se faz pelo caminho de compreensão que enxerga a família não como um núcleo isolado da vida social, mas como um núcleo em interação dialética com a vida social. E, do ponto de vista social, há sensíveis mudanças no mundo do trabalho que não foram ainda devidamente categorizadas para dentro das reflexões do âmbito da família contemporânea e seus problemas, do ponto de vista sócio-filosófico.

A família, certamente, não surgiu na era burguesa. A história desse processo de formação e institucionalização remonta a um mais prolongado estudo das etapas de consolidação da própria vida sedentária humana. ${ }^{11}$ Nesse sentido, esse percurso não interessa no interior dessa investigação, na medida em que o que se quer estudar é a problemática condição da família na passagem da modernidade à pós-modernidade, ou com Zygmunt Bauman, da modernidade sólida à modernidade líquida. Por isso, o que importa dizer é que a marca da modernidade é o crescente processo de privatização das

\footnotetext{
${ }^{10}$ FROMM, Erich. Ter ou Ser? Tradução de Nathanael C. Caixeiro. 4. ed. São Paulo: LTC, 1987. p. 45.

11 Marx possui suas hipóteses para esse estudo. Vide MARX, Karl. A origem da família, da propriedade privada e do Estado. In: Obras escolhidas. Rio de Janeiro: Vitória, s.d. p. 21-25.
} 
funções da família, na medida em que ela vai vivenciando a desocupação do público de seu interior, e deixando para a vida pública um número maior de atividades. ${ }^{12}$

Para além do fato de ser uma instituição natural, a família é também uma construção social, pois seus papéis variam conforme conjunturas e pressões específicas da sociedade. Ainda, para além da investigação sobre se a idéia de família surgiu ou-não na era burguesa, ou ainda se a família é ou-não algo que responde à natureza humana, podese dizer que uma certa concepção de família emergiu do contexto burguês, esta idéia de família expressando a identidade de um tempo, cuja significação aparece ao lado de todo um outro aparato de conceitos formador da identidade do mundo moderno. De um lado, o Estado nacional unificado, de outro, a sociedade civil, composta pela família, pelas empresas e pelo indivíduo. ${ }^{13}$ Por definição, nesse contexto, a família está em oposição ao espaço do público, e compartilha espaço com a personalidade do indivíduo e com a produtividade interessada dos agentes econômicos. Por isso, a família, nesse seu entorno, haverá de representar algo socialmente, de modo que, na era burguesa, se projeta no casamento e no sentimento do núcleo familiar uma idéia instrumental, a de que ambos servem como suportes ou acessórios das relações sociais de poder, especialmente do poder econômico. No texto O futuro do matrimônio (Die Zukunft der Ehe), de 1966, é Horkheimer quem afirma: "Con el progreso de la ilustración el matrimonio se convierte cada vez más claramente en un instrumento." 14 Assim como as estratégias sociais estão vertidas para a afirmação dos intentos acumulativos, a burocratização estatal se processa como forma de afirmação da legitimidade independente do Estado, também se planifica na família o ideal de garantia das condições subestruturais do método de produção. ${ }^{15} \mathrm{~A}$ família é o estrado sobre o qual dormem os interesses hegemônicos da classe burguesa. ${ }^{16}$

\footnotetext{
12 “À primeira vista, a evolução da família é simples: ela perdeu suas funções públicas e passou a ter funções privadas. Uma parte das tarefas antes confiadas a ela foi gradualmente assumida por instâncias coletivas; com essa socialização de certas funções, restou-lhe apenas a realização da vida privada. Nesse sentido, podemos falar de uma 'privatização' da família” (PROST, Antoine. A família e o indivíduo. In: PROST, Antoine; VINCENT, Gérard )Orgs.). História da vida privada. São Paulo: Companhia das letras, 1992. v. 5, p. 61).

13 "La famílla reducida es sólo un momento de la generalización de la Lonely Crowd, de la soledad en el todo nacionalizado" (HORKHEIMER, Max. Sociedad, razón y libertad. cit., p. 100).

14 Id. Ibid., p. 103.

15 "Al igual que otros momentos o elementos constitutivos de la sociedad, la relación entre los sexos es determinada y planificada de modo creciente con vistas a su utilidad para el estado de cosas existente" (Id. Ibid., p. 103).

16 "En cuanto actividad consciente, esta función de la familia fue especialmente realizada en la época de la Reforma y del absolutismo. Acostumbrar al individuo a no desesperar en aquel duro mundo de la nueva disciplina de trabajo en constante expansión, a estar a la altura de las circunstancias, exigía que la fría desconsideración hacia si mismo y hacia otros se convirtiera en algo natural en él" (HORKHEIMER, Max. Autoridad y familia y otros escritos. Traducción de Román G. Cuartango. Barcelona: Paidós, 2001. p. 207). Do ponto de vista da historiografia: "Mas, nessa sociedade em que os valores domésticos ocupam um lugar central, é essencial que o casamento se consume. Quando a família é a célula básica da sociedade, a união conjugal deve se tornar pública" (PROST, Antoine. op. cit., p. 77).
} 
Mas, a consciência burguesa de mundo gera uma modificação na interpretação do sentido de mundo desempenhado pelas coisas, donde se podem extrair os efeitos do que se processa no interior da modernidade, a partir da própria constatação de Marx: "A burguesia rasgou o véu do sentimentalismo que envolvia as relações de família e reduziu-as a simples relações monetárias" ${ }^{17}$ Ora, como tudo que é acessório, diz o jargão, segue o principal, então, a família segue hoje os rumos desenfreados da mudança que se processa no interior do Capital. Da moderno-pesado ao moderno-leve, o que se tem são transformações do sistema de produção, dos mecanismos de produção e das relações de produção. O sistema do capital se globalizou, e a globalização exige um indivíduo sempre pronto para relações de trabalho cada vez mais 'conectadas' e informais; exige, portanto, um ser ubíqüo, que vive entre Londres e Tóquio, que não possui apelo nacionalista, e que vive permanentemente em trânsito. Jean-François Lyotard já adiantava, em seu livro Condição pós-moderna: "Esta orientação corresponde à evolução das interações sociais, onde o contrato temporário suplanta de fato a instituição permanente em matérias profissionais, afetivas, sexuais, culturais, internacionais, assim como os assuntos politicos". ${ }^{18}$ A exigência de produção desse indivíduo-leve e disponível para o mercado responde às necessidades produtivas hodiernas, na medida em que a personalidade se molda no entorno das pressões e exigências do mundo do trabalho, de modo que o efeito reverso é que acaba se tornando pesada a forma sólida da família do início da modernidade produtivista e, por isso, um suplemento desnecessário e redundante para o modo de produção atual.

Nesse sentido, o que se percebe é que uma série de transformações da vida moderna, como a urbanização, a aceleração das exigências de qualificação para o trabalho, o aumento da competitividade nas relações de trabalho, a pauperização da remuneração do trabalho, a informatização e o distanciamento das relações entre trabalhador e empresa... trouxeram novos desafios à sociedade que não passariam distante de afetar diretamente a identidade da família. Os laços se afrouxam e sua éthos interior se degrada. ${ }^{19}$ A casa perde a força centrípeta que possui de drenar o olhar para dentro, e os olhares são cada vez mais direcionados ao exterior, donde a auto-identidade de seus membros se tornar cada vez menos aderente e cada vez mais escorregadia.

${ }_{17}$ MARX, Karl; ENGELS, Friedrich. Manifesto do partido comunista. In: Obras Escolhidas. Rio de Janeiro: Vitória, 1956. v. 1, p. 28.

${ }^{18}$ LYOTARD, Jean-François. Condição pós-moderna. Tradução de José Bragança de Miranda. 2. ed. Lisboa: Gradiva, 1989. p. 131.

19 "Las transformaciones del último siglo, sobre todo el paso de la familia extensa a la reducida al matrimonio y a los hijos, son discutidas hoy por doquier. Los abuelos, los tíos y las tías, los primos y primas, incluso los hijos e hijas adultos, que en otro tiempo mantenían una estrecha vinculación en las propias ciudades, apenas si guardan hoy una laxa relación” (HORKHEIMER, Max. Sociedad, razón y libertad. cit., p. 100). 
As pressões por unidade cedem em direção a pressões por realização individual; o indivíduo se destaca para deixar de ser parte de um coletivo em pequena escala, pois a individualidade compete com esta característica. "O individualismo, que em seu sentido positivo significa libertação das cadeias sociais, significa, no sentido negativo, autopropriedade, o direito - e o dever - de investir a própria energia no sucesso da própria pessoa" $\cdot{ }^{20}$ Há um decréscimo de cooperativismo e solidarismo sociais que, em primeira instância, são sentidos no interior da própria família. Afinal, a moral moderna (sólida ou tradicional) foi convertida na moral pós-moderna (líquida ou individualizante), esta última capaz de estimular, no máximo, provisórias “comunidades".

Quando a sociedade se liquidifica, isto quer dizer que a sociedade tem no novo método de produção uma nova alternativa de ação econômica estratégica. Por isso, torna-se irrelevante, ou mesmo um obstáculo, em determinados momentos, a formação do núcleo familiar. Se a família teve sentido num determinado momento do processo produtivo capitalista, agora ela se torna redundante. Com isto, as próprias categorias que dão suporte ao processo de formação da identidade do núcleo do lar são alteradas, daí não excluídas as idéias de amor, cortejo, galanteio, pureza, nome de família como sobrenome do homem, sacralidade do ritual de passagem, casamento. ${ }^{21}$ Todas estas idéias, acessórias, acompanhavam com ideologia a formação do próprio núcleo familiar, e significavam enquanto forma de dar estruturação à formação do núcleo familiar burguês. Todos esses elementos passam, portanto, por uma de-significação. Essa de-significação é somente um indício de um processo de mutação, talvez primeiro e ainda letárgico, e mesmo, da própria desaparição destas categorias, para vaticinar com Horkheimer. ${ }^{22}$

Ainda mais, o capitalismo hoje não carece mais de voltar-se para a casa (a mulher da mídia americana, feliz com um eletrodoméstico novo), como objeto predileto de ataque da especulação comercial, pois este não é mais o foco, nem de atenção, e nem de rentabilidade. A esfera da casa, da família é a esfera da necessidade, da sobrevivência, enfim, do indispensável para viver. Não é mais para responder a estas necessidades que se

\footnotetext{
${ }^{20}$ FROMM, Erich. Ter ou Ser? Tradução de Nathanael C. Caixeiro. 4. ed. São Paulo: LTC, 1987. p. 83.

21 "Exactamente lo mismo sucede con lo que se llama amor. Cuando el matrimonio burgués aún estaba relativamente intacto en las capas sociales en las que tenía vigencia y significado $-\mathrm{y}$ con vistas a los herederos del propio linaje - presuponía en la muchacha la pureza, en el hombre joven, la solicitud y el cortejo. Lo inicialmente negado o, en cualquier caso, dificultado, se convertia precisamente por eso, sobre todo mediante la correspondiente educación, en algo anhelado, valioso, pleno" (HORKHEIMER, Max. Sociedad, razón y libertad. Traducción e introducción de Jacob Muñoz Veiga. Madrid: Editoria Trotta, 2005. p. 107).

22 "Con ello he indicado ya mi representación del futuro del matrimonio. Por mucho que sus formas burguesas pueda perdurar aún, la conciencia de una unión que es, en cada caso, única, el significado del apellido, la voluntad de configurar la vida de acuerdo con cuanto viene a él unido y concuerda con él y, si es posible, de prolongar-lo a través de los hijos, está en trance de desaparición" (Id. Ibid., p. 108).
} 
destinam os esforços da mídia, mas sim para atender à necessidade de tornar obrigatório o que é supérfluo, quando o foco não é mais a família e sim o indivíduo-consumista (a mulher autônoma, da academia, esteticamente impecável, profissionalmente exemplar). Há uma mudança de imagens, mas a manutenção de uma mesma lógica dissolutória, na medida da conveniência de mercado. Assim como a mulher-feliz-consumidora-deeletrodomésticos dos anos 50, consumidora de produtos para o lar (a técnica voltada para o lar-sede-do-consumo), que pressupunha a coerência de ser si mesma e ser para a família, o ideal que exsurge em nosso tempo é o da mulher-feliz-super-malhada-com-tempo-para-si, consumidora de produtos para si (estética, lazer, viagem, moda, academia - o indivíduosede-do-consumo), que desvincula o ser si mesma e o ser do grupo família.

A coerência da família é somente acessória da coerência interna do próprio mercado. Por isso, a família acompanha o fluxo do mercado, de um mercado que se desloca para o abstrato do espaço de circulação intensa da economia globalizada, acarretando uma mudança de função para a família. Com Antoine Prost, pode-se concluir: " $A$ mudança de funções acarreta uma mudança de natureza: na verdade, a família deixa de ser uma instituição forte; sua privatização é uma des-institucionalização. Nossa sociedade se encaminha para familias informais". ${ }^{23}$

\section{A individualização do doméstico}

Para que se possa dar continuidade a esta investigação, cumpre ressaltar que não é possível considerar a história da família na modernidade como um monobloco. Isso já se percebe pelo percurso anterior. Ao longo do século XX, especialmente, as fases da família podem ser sintetizadas em três períodos: a da família que possui correspondência no casamento-imposição (dever pelo dever), ${ }^{24}$ no casamento-amor (dever e romantismo), e, em seguida, no casamento-opção (abaixo o dever) e, afinal, amor-sem-casamento (prazer em rotação), ou seja, no amor líquido. ${ }^{25} \mathrm{O}$ que se constata é o aumento de elasticidade na concepção de casamento, ao mesmo tempo em que deixa de ser uma tarefa indispensável socialmente, para se tornar um complemento adicional da vida profissional do indivíduo,

\footnotetext{
${ }^{23}$ PROST, Antoine. A família e o indivíduo. In: PROST, Antoine; VINCENT, Gérard (Orgs.). História da vida privada. São Paulo: Companhia das letras, 1992. v. 5, p. 61.

24 "La obstinación el niño debe ser quebrada y el deseo originario de libre desarrollo de sus impulsos y capacidades tiene que ser sustituido por la compulsión interna a un incondicional cumplimiento del deber. La subordinación bajo el imperativo categórico del deber ha sido desde un principio un objetivo consciente de la familia burguesa" (HORKHEIMER, Max. Autoridad y familia y otros escritos. Traducción de Román G. Cuartango. Barcelona: Paidós, 2001. p. 208).

${ }^{25}$ Cf. PROST, Antoine. op. cit., p. 89-91.
} 
o que certamente compromete a idéia que se havia firmado de família anteriormente, como sustentáculo do processo produtivo. De sustentáculo, ela passa a obstáculo.

A efemeridade toma conta do ambiente para trocar os sinais com a realidade duradoura, estável, centralizada e, em um termo, pesada, da família. ${ }^{26}$ Quando o transitório ocupa o espaço do que é revestido de algum incondicionamento, e neste caso estava a idéia de uma união perpétua, o resultado é uma desestruturação em escala dos valores que davam suporte e sustentação à união matrimonial. ${ }^{27}$

No lugar das relações estáveis, o mundo do amor líquido forma um mercado das “conexões rápidas" (acentue-se, no novo vocabulário, “conexões”, e não "relações”), úteis e disponíveis. Neste mercado da afetividade volátil, alter aparece como um outromercadoria que é consumido e de quem se dispõe transitoriamente como objeto, até quando outro produto mais útil aparece em sua substituição. $\mathrm{O}$ ritmo da afetividade vem marcado pelo timing de mercado, pelo tempo dos produtos que se sucateiam e se tornam obsoletos. ${ }^{28} \mathrm{O}$ amor líquido é a demonstração exemplar da capacidade dissolutória do capital, que desarranja instituições basilares como a família. A volatilidade do capital contemporâneo imprime ao amor uma feição liquefeita.

Quanto maior a instrumentalização da vida social pelas determinantes do mercado, maiores as conseqüências para a vida do indivíduo, e ainda maiores os efeitos sobre a dinâmica da individualização. "Cuanto más regulada esté la sociedad, tanto más instrumentales son las relaciones humanas, tanto mas carente de sentido la entrega al individuo singular". ${ }^{29}$ Habermas avança no sentido de dizer que sociedade, cultura e personalidade são colonizadas pelo poder econômico, quando se tem a reificação da esfera do mundo da vida. ${ }^{30}$

Além da mudança produtiva, outros processos colaboraram para a formação desse quadro que hoje afeta a estrutura da família que se conhece, gerando a sensação de

\footnotetext{
26 "No conozco ninguna investigación empírica acerca de la influencia de este progreso sobre la relación humana incondicional; mi hipótesis es que la nueva liberalidad, como el colectivismo, por otra parte, no le resulta favorable. En ambos casos se anuncia lo mismo, desencantamiento de lo efímero, único, irrepetible". (HORKHEIMER, Max. Sociedad, razón y libertad. cit., p. 109).

27 "El momento de lo absoluto desaparece del arte enteramente libre como del matrimonio libre. Los cuadros abstractos pertenecen a la instalación funcional, los matrimonios sin prejuicios a la existencia adaptada. El retorno es imposible. La fidelidad indisoluble entre dos seres humanos como felicidad y sentido de sus vidas pasa a convertirse con cada percepción más amplia de lo condicionado de la persona y de cuanto a ella corresponde, en mero delirio, no menos que la eternización del paisaje y del pequeño campesino en el óleo. El futuro que puede corresponderles tanto a los valores estéticos como al matrimonio es comprado al precio de una reducción de su importancia y significado" (Id. Ibid., p. 110).

28 BAUMAN, Zygmunt. op. cit.

29 HORKHEIMER, Max. Sociedad, razón y libertad. cit., p. 106.

${ }^{30}$ A respeito, vide HABERMAS, Jürgen. Consciência moral e agir comunicativo. Tradução de Guido A. de Almeida. Rio de Janeiro: Tempo Brasileiro, 1989.
} 
crise e a necessidade de busca de nova identidade. Ao lado das questões ligadas ao mundo do trabalho, e interconectadas a elas, pois não há cultura fora da história e dos reflexos econômicos, no pós-guerra se conhece uma profunda mudança de costumes, gerando uma reavaliação imensa de valores e arquétipos sócio-culturais. Nesse contexto, especialmente de maio de 68 e de Woodstock têm lugar uma das maiores revoluções culturais dos tempos modernos: ${ }^{31}$ movimento estudantil, rebeldia juvenil, revolução estética, quebra de padrões, freudianização do debate político, ascensão do feminismo, eclosão de revoltas. ${ }^{32}$ Muitos desdobramentos serão constatados ecoando positivamente muitas décadas depois destes eventos, mas algumas são mais perceptíveis: liberalização sexual, equiparação de direitos da mulher aos do homem, quebra do autoritarismo familiar. ${ }^{33}$ No entanto, o que se há de verificar é que essa conta não se paga sem um saldo negativo.

Se, no início do século XX, a vida familiar implica em convívio, em estar junto, em comprimir-se num mesmo espaço (une pièce pour tous), após jornadas extenuantes de trabalho, a idéia de privacidade era uma idéia escassa para a grande maioria da população. ${ }^{34} \mathrm{~A}$ família como suporte da vida do trabalho é sustentáculo. A idéia de dever está a presidir os rumos da domesticação dos instintos no nível do privado, desde a mais tenra idade; nesse ambiente, o lugar do prazer e da intimidade é uma exceção controlada. ${ }^{35}$ Sua interna distribuição de deveres implica em uma ética rigorosa, e também capaz de antecipar as duras condições de sobrevivência quando da entrada dos filhos no mundo do trabalho. O éthos familiar está condicionado, em todas as escalas, conscientes e inconscientes, à lógica do trabalho. Por isso, o marido é o chefe, a mulher e os filhos

31 É o mundo dos jogos de linguagem com seus determinismos locais: “Assim, a sociedade que se avizinha revela menos de uma antropologia newtoniana (como o estruturalismo e a teoria dos sistemas) e mais de uma pragmática das partículas de linguagem. Há muitos jogos de linguagem diferentes: é a heterogeneidade dos elementos. Eles permitem a instituição apenas por sectores: é o determinismo local" (LYOTARD, JeanFrançois. Condição pós-moderna. Tradução de José Bragança de Miranda. 2. ed. Lisboa: Gradiva, 1989. p. 12).

32 "Os costumes, no entanto, se modificam. O feminismo encontra uma nova repercussão, amplificada pelos acontecimentos de 1968" (PROST, Antoine. op. cit., p. 91).

33 "La equiparación de la mujer al hombre, su actividad profesional, la emancipación mucho más rápida de los hijos, traen ya consigo una transformación de la atmosfera del hogar. En América no es raro que el padre sienta que se ha quedado ya retrasado frente al hijo. Como la existencia sin más, el matrimonio tiende a convertirse en algo cada vez más racional, más funcional y más sobrio" (HORKHEIMER, Max. Sociedad, razón y libertad. cit., p. 109).

34 Toma-se o caso da França como exemplo, mas a afirmação pode ser generalizada: "No começo do século, portanto, a vida privada da imensa maioria dos franceses se confundia, devido ao espaço, com a de seus familiares" (PROST, Antoine. op. cit., p. 73).

35 "A la luz de la conciencia cultural, el placer ha sido confinado en el triste refugio del zote pequeño burgués y en la prostitución" (HORKHEIMER, Max. Egoísmo y movimiento liberador. In: y otros escritos. Traducción de Román G. Cuartango. Barcelona: Paidós, 2001. p. 78). . Autoridad y familia 
os subalternos, ao menos do ponto de vista dos papéis sociais formais. ${ }^{36}$ A hierarquia e a disciplina fabris são transportadas do ambiente do trabalho e da esteira de produção para dentro da organização e disciplinação das relações familiares.

As alterações produtivas, com a entrada de uma era do trabalho na sociedade de serviços e, em seguida, da informação, a abastança do pós-guerra, a revolução dos costumes, trazem consigo modificações que vão ser percebidas no interior do núcleo familiar. Ao longo do século XX, o que se constata pela historiografia é que, de fato, nãosomente os ambientes domésticos se alargam, mas também que a esfera do indivíduo se alarga em seu interior e para fora dele. ${ }^{37}$

Com a crescente individuação da vida contemporânea, o lar perde um tanto de sua significação. Com isso, os pais, indivíduos sobrecarregados por jornadas de trabalho informalizadas e tornadas flexíveis, mas que ocupam mais tempo que a jornada de trabalho regulamentada, e superocupados com questões ligadas à afirmação de sua própria egocentria, descarregam sobre instituições sociais algumas tarefas antes consideradas privadas. ${ }^{38}$ Nesse sentido, há uma publicização da relação de formação do indivíduo, no sentido de uma delegação de responsabilidade à escola-total, à escola em cujo contrato devem estar embutidas as responsabilidades por alimentar, suprir afetivamente, moldar o caráter, preparar para o vestibular, domesticar a fúria infantil, curar os desvios psíquicos, etc. ${ }^{39}$ É claro que nessas condições somente há transferência de responsabilidades, num perverso processo de diluição da responsabilidade formativa. Em Mudança estrutural da esfera pública (Strukturwandel der Öffentlichkeit: Untersüchengen zu einer Kategorie der bürgerlichen Gesellschaft), de 1962, Habermas traça o percurso dessa problemática

\footnotetext{
36 "A família exercia um controle bastante rigoroso sobre seus próprios membros. O marido era o chefe da família; a mulher casada precisava ter sua autorização por escrito para abrir conta no banco ou para administrar seus próprios bens" (Prost, A família e o indivíduo, in História da vida privada, vol. 5, 1992, p. 77). "Se é possível discutir a divisão dos poderes entre o marido e a mulher na sociedade pré-1950, o poder dos pais sobre os filhos é inquestionável: os filhos não tinham qualquer direito a uma vida privada" (PROST, Antoine. A família e o indivíduo. In: PROST, Antoine; VINCENT, Gérard (Orgs.). História da vida privada. São Paulo: Companhia das letras, 1992. v. 5, p. 78).

37 “A diversificação e a ampliação da vida privada na segunda metade do século XX não se limitam ao âmbito doméstico. A conquista do espaço da vida privada não é apenas a do espaço familiar: é também a conquista dos meios de sair dele" (Id. Ibid., p. 76).

38 "Lo que si me parece seguro es que la autoridad de los padres sobre los hijos, sobre todo la del padre, disminuirá rapidamente. Su experiencia profesional y vital pierde en importancia, los hijos se convierten más rapidamente en adultos, el control de los jóvenes por los padres resulta cada vez más difícil. La educación pasa cada vez más a manos no solo de la escuela, que ya de por si cumple tareas que son de orden profesional más bien que formativas en sentido genuíno, sino de los médios de comunicación de masas, de la televisión, de la radio y del cine. Para los padres se ha convertido en una tarea irrealizable. En la medida en que el marido y la esposa tienen una profesión, los anos en lo que esta ha de ocuparse de su descendencia se convierten en una interrupción de su carrera” (HORKHEIMER, Max. Sociedad, razón y libertad. cit., p. 110-111).

39 "Os pais descarregavam sobre a escola a tarefa de ensinar aos filhos as regras da vida em sociedade; cabe-lhes ainda alimentá-los, vesti-los e principalmente amá-los, mas sob o controle do poder público que julga em última instância se estão se desincumbindo bem da tarefa" (PROST, Antoine. op. cit., p. 87).
} 
com clareza: "Proporcionalmente à perda de suas tarefas econômicas, a família perdeu complementarmente também a força para a interiorização pessoal. Diagnosticada por Schelsky, essa tendência à retificação das relações intra-familiares corresponde a uma evolução em cujo transcurso a família é cada vez menos solicitada como agência primordial da sociedade. O muito citado desmantelamento da autoridade paterna, uma tendência, observável em todos os países industrializados avançados, no sentido de contrabalançar a estrutura de autoridade intrínseca à família, pertence ao mesmo contexto. Agora, os membros individuais da família passam a ser socializados em maior escala por instâncias extra-familiais, pela sociedade de modo imediato; basta lembrar aqui aquelas funções explicitamente pedagógicas que a família burguesa teve de entregar formalmente à escola, informalmente a forças anônimas fora do lar. A familia, que é cada vez mais excluída do contexto imediato da reprodução da sociedade, só na aparência é que mantém com isso um espaço intrínseco de privacidade intensiva: na verdade, tendo perdido as suas tarefas econômicas, ela também perde as suas funções de proteção; exatamente à pretensão econômica da família patriarcal strictu sensu correspondia, de fora, a força institucional para a formação de um domínio da interioridade que, hoje, abandonado a si mesmo, sob o ataque de instâncias extrafamiliares, começou a se dissolver numa esfera da privacidade aparente, a se reduzir imediatamente ao indivíduo". ${ }^{40}$

Os filhos acostumados a encontram no privado este vazio e no público este aconchego, fazem do lar uma rota de passagem, um lugar de encontros de individualidades. Vale a pena acompanhar a leitura de Antoine Prost, quando afirma: "Assim, a família perde gradualmente as funções que a caracterizavam como uma microssociedade. A socialização dos filhos abandonou em larga medida a esfera doméstica. A família, portanto, deixa de ser instituição para se tornar um simples ponto de encontro das vidas privadas". ${ }^{41}$ Não de se estranhar, portanto, em continuação, afirma o historiador, que "...a afirmação da vida privada de cada indivíduo corrói internamente a instituição familiar". ${ }^{42}$ Em síntese: " $A$ relação do indivíduo com a família se inverteu. Hoje, exceto na maternidade, a família não é senão a reunião dos indivíduos que a compõem nesse momento; cada indivíduo tem sua própria vida privada e espera que esta seja favorecida por uma família de tipo informal". ${ }^{43}$

\footnotetext{
40 HABERMAS Jürgen. Mudança estrutural da esfera pública: investigação quanto a uma categoria da sociedade burguesa. Tradução de Flávio R. Kotle. Rio de Janeiro: Tempo Brasileiro, 1984. p. 186.

41 PROST, Antoine. op. cit., p. 87.

42 Id. Ibid., p. 92. “Além do casamento, a própria família é abalada. O lar formado por um casal e filhos já não é a norma exclusiva: as famílias com apenas um genitor são cada vez mais freqüentes".

${ }^{43}$ Id. Ibid., p. 94.
} 
5. Autoridade, família e educação

Não há dúvida de que a família tem um papel preponderante na formação e no amoldamento da personalidade e da psyché humanas, agindo tanto por mecanismos conscientes como por mecanismos inconscientes. ${ }^{44} \mathrm{~A}$ afetação da família pela individualização, paradoxalmente, não significa simplesmente um passo adiante, na medida em que os resultados mais danosos parecem se produzir especialmente na dimensão do indivíduo.

A reflexão sobre a perda da autonomia na formação do indivíduo começa, portanto, com um estudo da heterologia, ou seja, com um estudo das formas pelas quais socialmente se constróem imagens que se superpõem à força de autoconstituição do indivíduo autônomo. $\mathrm{O}$ enfraquecimento do caráter e da autonomia se dá em função da desproporção das respostas entre as perguntas sobre o ser e sobre o ter, dadas por nossa sociedade.

Mais ainda, a família burguesa do pós-guerra cuida, na formação do caráter, de impedir com que uma consciência das contradições sociais reais chegue aos olhos dos filhos, que, de dentro de uma redoma, enxergam o mundo apenas sob a ótica protecionista de seus pais; as diferenças sociais e as clivagens classiais não pertencem ao universo de formação das novas classes burguesas. A consciência de mundo já aparece, aos olhos do jovem, imediatamente como consciência reificada. ${ }^{45} \mathrm{O}$ que se experimenta, portanto, ao longo do século XX é um processo de substituição da ética familiar autoritária, ${ }^{46}$ numa passagem que vai em direção à falta completa de paradigmas.

No entanto, é notório que há progressos substanciais nas grandes conquistas referidas à emancipação dos filhos e das mulheres, e isto é inegável. Juntamente com Erich Fromm se pó de dizer: "Embora a revolução política do século $X X$, a revolução russa, tenha fracassado, as revoluções vitoriosas de nosso século, embora ainda estejam nas primeiras fases, são as das mulheres, dos filhos e a sexual' ${ }^{47}$ Ainda nessa linha,

\footnotetext{
${ }^{44}$ No texto de 1936: "La familia tiene un significado sobresaliente entre la relaciones que influyen decisivamente en el moldeamiento psíquico de la mayor parte de todos los individuos, tanto mediante mecanismos conscientes como inconscientes" (HORKHEIMER, Max. Autoridad y familia. In: escritos. Traducción de Román G. Cuartango. Barcelona: Paidós, 2001. p. 207). Autoridad y familia y otros

45 "Las ideologías del rendimiento y del mérito, de la armonía y la justicia, encuentran también un lugar en esa imagen del mundo, porque la contradicción no entra en la conciencia a causa de la cosificación de las diferencias sociales" (Id. Ibid., p. 215-216).

46 "La familia, como una de las instancias educativas más importantes, se preocupa de la reproducción de los caracteres humanos, como exige la vida social y les confiere en gran parte la aptitud indispensable para el comportamiento específicamente autoritário, del que depende ampliamente la existencia del orden burgués" (Id. Ibid., p. 207).

${ }^{47}$ FROMM, Erich. Ter ou Ser? Tradução de Nathanael C. Caixeiro. 4. ed. São Paulo: LTC, 1987. p. 87.
} 
pode-se dizer que o maior ganho está na busca de genuinidade e correspondência entre o sentimento verdadeiro e a prática verdadeira, tendo-se deixado para trás, em grande parte, a hipocrisia que marcava a vida pequeno-burguesa, especialmente ante o contraste entre a rigidez autoritária e a espontaneidade requerida, o prazer e o dever, a severidade e a descontração, a reprodução e a luxúria. ${ }^{48}$ Mas, estas lutas ainda não se plenificaram em conquistas acabadas, tendo em vista que os efeitos colaterais do processo têm sido igualmente danosos, do ponto de vista intersubjetivo e intrasubjetivo.

O resultado da crise da família é o enfraquecimento da capacidade de autonomia do indivíduo; a noção de felicidade é uma confusa concepção a orientar a vontade assoberbada da vida privada hodierna. É numa era em que se busca obstinadamente a felicidade por si mesma que se vê a felicidade comprometida e ameaçada. ${ }^{49}$ Por isso, com a formação debilitada, com o amadurecimento retardado para os desafios da vida e da profissão, com o amparo psico-afetivo incompleto, com a dependência financeira permanente dos pais, cada vez menos os indivíduos se sentem capazes de exercer a autonomia, ou seja, a capacidade de se dar normas, e, nesse sentido, de estar na posse e no exercício de si mesmos.

Nesse sentido, como o indivíduo tem o seu decreto de nascimento no interior da família, e como nível de socialização primordial, o enfraquecimento das instituições ligadas à identidade familiar trazem como conseqüência a própria desestruturação do indivíduo-ele-mesmo, pois a sensação de desnorte é acompanhada pela dúplice perspectiva, de um lado, as pressões por uma abertura de alternativas e possibilidades de escolha, de outro lado, o decréscimo da capacidade de exercer, com autonomia e responsabilidade, escolhas, uma vez que a orientação primordial parte da identidade do próprio núcleo familiar. O prejuízo social é incomensurável, na medida em que os efeitos em cascata são sucessivos e ininterruptos.

Em tese, a escola teria uma grande tarefa a enfrentar, mas a própria escola deixou de cumprir esse papel, na medida em que reificada foi a sua estrutura, de instituição preservadora da cultura, a relação de consumo mediada pela lógica do lucro. Aulas que são a repetição de fórmulas massificadas de reprodução de informações se tornam o jargão comum do universo banalizado do saber. Num jogo de empurra-empurra, o dever

\footnotetext{
48 "No entanto, foi banida a rigidez da antiga adoração aos pais e outras autoridades, e parece certo que a velha reverência para com a autoridade não voltará” (FROMM, Erich. Ter ou Ser? Tradução de Nathanael C. Caixeiro. 4. ed. São Paulo: LTC, 1987. p. 187).

49 "Se confunde la felicidad con quedar a salvo de los golpes del destino y de los conflictos de conciencia, lo que significa la libertad relativa respecto de los dolores y los miedos externos e internos, un estado neutral y a menudo sombrío, en el que el alma parece vacilar entre la actividad y la apatía" (HORKHEIMER, Max. Egoísmo y movimiento liberador. cit., p. 78).
} 
de formação torna-se algo tão minguado, que recebe um tratamento de irresponsabilidade, na sociedade da liquefação das instituições: o casal acredita que a babá está criando, a babá acredita que a escola está criando, e a escola acredita que a família está criando. Uma formação que recebe parcelas de irresponsabilidades graduais, que se somam ao longo da história do indivíduo, culminando com carências psicoafetivas, intelectuais e morais incontornáveis na idade adulta.

É pela perda de referências que se experimenta crescentemente mais a eleição de símbolos, heróis e ícones, onde outras gerações encontrariam apenas as evidências da boçalidade, do exibicionismo e da ignorância. Quando massas inteiras são tomadas pelos ícones mercadurizados (indivíduos que são, no fundo, utensílios do mercado) e gravam sobre eles depósitos crescentes de autoprojeção, constrói-se um imaginário social fundado na inconseqüênte inconsistência de suas personalidades individuais. ${ }^{50} \mathrm{O}$ frenesi dos fãs do rock, a espetacularização da política, o enfraquecimento do sistema educacional, e o descolamento da família são os caminhos convergentes que conduziram a este processo de enfraquecimento da autonomia de entronização da irresponsabilidade para o centro da vida política nacional. É novamente em O futuro do matrimônio, de 1966, que Horkheimer se pronuncia, com inigualável sensibilidade, a respeito do tema: "En las postrimerías del período burgués y de su injusticia específica, con la victoria de la época técnica de él resultante, el aura de la persona se apaga. Mediante la presentación no elegida y la conversión activa en imágenes públicas de las estrellas cinematográficas, de los líderes manchados de sangre, de las princesas en busca de marido, mediante la laboriosa personificación en los médios de comunicación de masas, a los que, obviamente, ya no queda otra cosa a mano, viene, por así decirlo, a confirmarse el final de la persona en sentido genuino". 51

O ser do nosso tempo converteu-se na negação de sua própria natureza; a perda da autonomia é o fruto dessa superficialização que se entrega como presa fácil à dimensão de uma exterioridade estéril que se destaca do egoísmo individual e social predominantes. Com todas as letras, estas palavras que servem para descrever o estado atual de coisas, serviam para Horkheimer proceder a uma antropologia da época burguesa, em seu texto, de 1936, Egoísmo e movimento liberador: para uma antropologia da época burguesa (Egoisumus und Freiheitsbewegung): "En la época actual, el egoísmo se ha

\footnotetext{
50 “... el esfuerzo por crear ídolos, sea en forma de personalidades, cosas o conceptos, a la necesidad de reconciliar de forma duradera a las masas con las tendencias de determinados grupos de la sociedad" (HORKHEIMER, Max. Egoísmo y movimiento liberador. In: G. Cuartango. Barcelona: Paidós, 2001. p. 84).

51 HORKHEIMER, Max. Sociedad, razón y libertad. cit., p. 106.
} 
vuelto de hecho destructivo, tanto el desatado y desviado egoísmo de las masas como el envejecido principio egoísta de la economía, que muestra sólo su lado brutal". ${ }^{2}$

A autonomia não se constrói fora do âmbito do autoconhecimento, que implica na possibilidade do indivíduo acessar a si mesmo a partir das configurações do mundo do ser. O constante processo de aprimoramento interno do indivíduo é substituído pelo imperativo de sua renovação para a enxurrada de produtos do mercado. Trata-se de um quadro politicamente perigoso, pois para toda uma geração o gozo se tornou um fim em si mesmo. Hoje, a extensão dos modos de dominação independe da consciência de que se trata de uma questão de ideologia burguesa, pois não é mais necessária uma ideologia burguesa para sustentar a dominação; a dominação já é sistêmica e plenificada. Uma vez inconscientizada, são massas inteiras que se encontram aprisionadas ao padrão, pois são múltiplos os fatores de alienação dispersos pela vida social (TV, consumo, especialização da política, tecnificação da educação, hedonismo). Por isso, a opressão se realiza com o consentimento da maioria, que não reconhece em si um sistema de dominação em operação... Dessa forma, são os próprios indivíduos oprimidos que rejeitam a autonomia. Novamente, é no texto de Horkheimer, de 1936, Egoísmo e movimento liberador: para uma antropologia da época burguesa (Egoisumus und Freiheitsbewegung), que se haverá de encontrar a seguinte enunciação: "Por todos los medios, tanto del convencimiento cuanto de la fuerza, les fueron inculcados la autodisciplina y el espíritu de conciliación entre ellos y frente a los dominadores. Los individuos fueron domesticados". 53

Conclusão

Trabalhando ainda na linha do rastreamento das conseqüências do processo de transição paradigmática, a discussão trazida por este artigo envidou esforços no sentido de demonstrar que as mudanças no mundo do trabalho trouxeram conseqüências muito específicas para dentro do universo da família.

Nesse sentido, como o indivíduo tem o seu decreto de nascimento no interior da família, e como nível de socialização primordial, o enfraquecimento das instituições ligadas à identidade familiar trazem como conseqüência a própria desestruturação do indivíduo-ele-mesmo, pois a sensação de desnorte é acompanhada pela dúplice perspectiva, de um lado, as pressões por uma abertura de alternativas e possibilidades de escolha, de

\footnotetext{
${ }_{52}$ HORKHEIMER, Max. Egoísmo y movimiento liberador. In: Traducción de Román G. Cuartango. Barcelona: Paidós, 2001. p. 146.

53 Id. Ibid., p. 76.
} 
outro lado, o decréscimo da capacidade de exercer com autonomia e responsabilidade escolhas, uma vez que o orientação primordial parte da identidade do próprio núcleo familiar.

Se a família implica em responsabilidade, renúncia, abdicação e esforço, é evidente que esta idéia está na contramão da história do presente, que se escreve em fórmulas hedonistas de falsa autorealização. O prejuízo social é incomensurável, na medida em que os efeitos em cascata são sucessivos e ininterruptos.

Ao mesmo tempo, percebe-se, ao longo da investigação que as categorias burguesas construíram conceitos que estruturaram a formação histórica de uma certa identidade de família que, agora, sob novos contextos produtivos e novas exigências do capital, se tornaram óbices ao individualismo contemporâneo e, exatamente por isso, caminha-se no sentido da desagregação da família, de modo que a conclusão não pode ser outra senão a de que o que importa não é o indivíduo e sua condição, especialmente seu bem-estar moral e psicológico; o que importa é o fim estratégico almejado, que a tudo instrumentaliza, inclusive a família.

A acomodação de todas estas transformações ainda não se consolidou, de modo que tudo indica que se vive ainda a transição paradigmática, mas que não exista ainda nenhum tipo de consolidação que registre a formação de uma nova identidade familiar, ao menos em tese, substitutiva da concepção anterior. Ainda nos encontramos em suspenso no ar; daí a sensação de indeterminação. Está-se na berlinda do tempo.

Ainda que a legislação crie designações, termos e vocabulários que introduzem novos registros na relação homem-mulher, bem como na relação pais-filhos, no interior do núcleo familiar, a questão é bem mais complexa, que toca a uma análise sociológica muito mais apurada. Tudo isto dá a entender o quanto a desestruturação dos arquétipos que orientavam a vida familiar tem repercussões na esfera da formação do indivíduo e determina sua inserção na socialização.

Talvez o excesso de renúncias no interior de um sistema opressivo, ${ }^{54}$ que, uma vez ruído, deu lugar ao seu oposto total, quando se vive de uma desmedida arbitrariedade no mundo do amor líquido. De qualquer forma, ainda que não se esteja na posse das condições de predizer o futuro, pressente-se, desde já, que o estado de coisas em que se vive não pode ter-se tornado definitivo, na medida em que contrasta em muito com a dinâmica normativa das concepções de vida possíveis.

\footnotetext{
54 "La nueva evolución evita cosas mucho más graves, a que daba lugar el sólido matrimonio burgués de otrora, la tirania de los maridos sobre mujer e hijos, la infelicidad, cuando la relación matrimonial, sentida como central, consistia en una cadena de renuncias." (HORKHEIMER, Max. Sociedad, razón y libertad. Traducción e introducción de Jacobo Muñoz Veiga. Madrid: Editorlal Trotta S. A., 2005. p. 111).
} 
Talvez estejamos ainda processando uma grande revolução e não estejamos ainda revestidos das condições para enxergar, além do presente, os bons frutos deste processo. Mas, antes que tenhamos essa lucidez, vale constatar, muitos prejuízos já terão se processado, destes que não retornam mais, destes que não se consertam mais.

São Paulo, fevereiro de 2007.

\section{Referências}

BAUMAN, Zygmunt. Amor Líquido: sobre a fragilidade dos laços humanos. Tradução de Carlos Alberto Medeiros. Rio de Janeiro: Jorge Zahar, 2004.

. Comunidade: a busca por segurança no mundo atual. Tradução de Plínio Dentzien. Rio de Janeiro: Jorge Zahar, 2003.

. Em busca da política. Tradução de Marcus Penchel. Rio de Janeiro: Jorge Zahar, 2000.

. O mal-estar da pós-modernidade. Tradução de Mauro Gama; Cláudia Martinelli Gama. Rio de Janeiro: Jorge Zahar, 1998.

. Modernidade líquida. Tradução de Plínio Dentzein. Rio de Janeiro: Jorge Zahar, 2001.

. Modernidade e ambivalência. Rio de Janeiro: Jorge Zahar, 1999.

BITTAR, Eduardo Carlos Bianca. O direito na pós-modernidade. Rio de Janeiro: Forense Universitária, 2005.

FROMM, Erich. Ter ou ser? Tradução de Nathanael C. Caixeiro. 4. ed. São Paulo: LTC, 1987.

HABERMAS, Jürgen. Consciência moral e agir comunicativo. Tradução de Guido A. de Almeida. Rio de Janeiro: Tempo Brasileiro, 1989.

. Mudança estrutural da esfera pública: investigação quanto a uma categoria da sociedade burguesa. Tradução de Flávio R. Kotle. Rio de Janeiro: Tempo Brasileiro, 1984.

HORKHEIMER, Max. Autoridad y familia y otros escritos. Traducción de Román G. Cuartango. Barcelona: Paidós, 2001.

. Crítica de la razón instrumental. Traducción de Jacobo Muñoz. Madrid: Trotta, 2002.

. Sociedad, razón y libertad. Traducción e introducción de Jacobo Muñoz Veiga. Madrid:

Editorial Trotta, 2005. 
HORKHEIMER, Max; ADORNO, Theodor W. Dialética do esclarecimento: fragmentos filosóficos. Tradução de Guido Antonio de Almeida. Rio de Janeiro: Jorge Zahar, 1985.

LYOTARD, Jean-François. A condição pós-moderna. Tradução de José Bragança de Miranda. 2. ed. Lisboa: Gradiva, 1989.

MARCUSE, Herbert. Eros e civilização: uma interpretação filosófica do pensamento de Freud. Tradução de Álvaro Cabral. 8. ed. Rio de Janeiro: LTC, 1999.

MARX, Karl. A origem da família, da propriedade privada e do Estado. In: Obras escolhidas. Rio de Janeiro: Vitória, s.d.

MARX, Karl; ENGELS, Friedrich. A ideologia alemã. Tradução de Luis Cláudio de Castro e Souza. São Paulo: Martins Fontes, 2001.

. Manifesto do partido comunista. In: Obras escolhidas. Rio de Janeiro: Vitória, 1956. v. 1.

PROST, Antoine. A família e o indivíduo. In: PROST, Antoine; VINCENT, Gérard. (Orgs.). História da vida privada. São Paulo: Companhia das Letras, 1992. v. 5, p. 61-114.

TÜRKE, Christoph. Sociedade da sensação: a estetização da luta pela existência. In: ZUIN, Antonio A. S.; PUCCI, Bruno; RAMOS DE OLIVEIRA, Newton. Ensaios frankfurtianos. São Paulo: Cortez, 2004. p. 61-74. 